\title{
Conditions required for the bactericidal activity of 4- quinolones against Serratia marcescens
}

\author{
C. S. LEWIN and J.T. SMITH*
}

\begin{abstract}
Department of Bacteriology, University Medical School, Teviot Place, Edinburgh EH8 9AG and "Microbiology Section, Department of Pharmaceutics, The School of Pharmacy, University of London, 29-39 Brunswick Square, London WC1N 1AX
\end{abstract}

\begin{abstract}
Summary. The conditions required to kill Serratia marcescens with nalidixic acid, ciprofloxacin, norfloxacin or ofloxacin were determined in nutrient broth and in phosphate-buffered saline. They were found to be similar to the conditions required for these 4-quinolones to kill Escherichia coli. Bacterial RNA synthesis and bacterial cell division were essential for the bactericidal activity of nalidixic acid but all three fluoroquinolones were bactericidal against non-dividing $S$. marcescens. However, as with E. coli, bacterial RNA synthesis was essential for the bactericidal activity of norfloxacin though this was not required to kill $S$. marcescens with ciprofloxacin or ofloxacin.
\end{abstract}

\section{Introduction}

Bacterial protein and RNA synthesis, as well as cell division, are essential for the non-fluorinated 4quinolones such as nalidixic acid and oxolinic acid to kill Escherichia coli. ${ }^{1-3}$ Therefore, it was proposed by Smith $^{2}$ that these drugs possessed a single bactericidal mechanism, termed $\mathrm{A}$, which required bacterial protein synthesis, RNA synthesis and bacteria capable of cell division to exert its lethal activity. Although these older 4-quinolones possess a single bactericidal mechanism, all eight of the modern fluorinated quinolones, that have been investigated, appear to exert another bactericidal mechanism, in addition to mechanism $A$, because they are active against non-dividing $E$. coli.

Ciprofloxacin, DR-3355, fleroxacin, ofloxacin, pefloxacin and lomefloxacin exhibit an additional mechanism, termed $B$, which does not require bacterial protein or RNA synthesis for its activity and is active against non-dividing bacteria. ${ }^{2-7}$ Even though protein synthesis and RNA synthesis are essential for the bactericidal activity of enoxacin and norfloxacin against $E$. coli, ${ }^{3,5,8}$ both of these drugs are, nevertheless, able to kill non-dividing E. coli. Therefore, it was proposed that they exhibited, as well as mechanism A, a second additional mechanism, termed C. ${ }^{3,5,8}$

In in-vitro experiments, $E$. coli mutates to resistance to the older 4-quinolones at higher frequencies than those observed with the fluoroquinolones. ${ }^{9,10}$

Received 18 Dec. 1989; accepted 11 Jan. 1990.
It has been suggested that this might occur because the latter drugs possess an extra bactericidal mechanism ( $B$ or $C$ ) whereas the older drugs possess only a single mechanism (A); therefore, two distinct mutations may be required to confer resistance to the fluorinated drugs whereas a single mutation may suffice to confer resistance to the older drugs. $2,9,10$

Studies by Watanabe et al. ${ }^{11}$ have shown that Serratia marcescens mutates in vitro to resistance to ciprofloxacin, ofloxacin and norfloxacin, at four times their MICs at higher frequencies than those observed with $E$. coli. Similarly, Smith has found that $S$. marcescens mutates to resistance to ofloxacin, at five times its MIC, at higher frequencies than those observed with $E$. coli. ${ }^{9,12}$ Furthermore, invivo, ofloxacin-resistant and ciprofloxacin-resistant mutants of this species have been isolated. ${ }^{1314}$ Two of the five strains that developed resistance to ciprofloxacin during therapy in the phase II and III trials of the drug were $S$. marcescens. ${ }^{13}$

Therefore, we have investigated the bactericidal mechanisms of fluoroquinolones against $S$. marcescens to establish whether they correlate with its ability to develop resistance to the fluoroquinolones, as has been observed with $E$. coli.

\section{Materials and methods}

\section{Bacterial strain}

S. marcescens 120 , a prototroph, was used throughout 
this investigation. The strain was kept on drug-free nutrient-agar plates which were subcultured every 10 days. Colonies taken from drug-free nutrient agar were used to inoculate the overnight cultures used in these experiments.

\section{Antibacterials}

Ciprofloxacin (Bayer UK) and norfloxacin (Merck, Sharpe and Dohme, UK) were dissolved in sterile distilled water, and ofloxacin (Hoechst UK) and nalidixic acid (Sterling, UK) in $0.5 \mathrm{M} \mathrm{NaOH}$ before being made up to appropriate concentrations in sterile distilled water. Rifampicin (Merrel Dow, UK) was dissolved in dimethylsulphoxide.

\section{Determination of antibacterial effects of the 4- quinolones}

The killing activity of the 4-quinolones was determined in nutrient broth at $37^{\circ} \mathrm{C}$ over a 3-h period with various drug concentrations. Survival was estimated by serial dilution in nutrient broth followed by viable counting on nutrient agar as described by Lewin et al. ${ }^{15}$

The rate of kill of bacteria treated with the 4-quinolones in nutrient broth or phosphate-buffered saline (PBS) was measured at $30-\mathrm{min}$ intervals over a 4-h period by viable counting on nutrient agar as described by Lewin and Smith. ${ }^{16}$

\section{Results}

Studies of the bactericidal activity of nalidixic acid, ciprofloxacin, norfloxacin or ofloxacin, separately, at various concentrations in nutrient broth over $3 \mathrm{~h}$ at $37^{\circ} \mathrm{C}$, showed a biphasic effect with $S$. marscescens (fig. 1). The bactericidal activity of the drugs increased until a concentration known as the most, or optimum, bactericidal concentration was reached. Higher concentrations then became progressively less bactericidal. The optimum bactericidal concentration of ciprofloxacin and norfloxacin against $S$.marcescens was $1.5 \mathrm{mg} / \mathrm{L}$ of ofloxacin 5-9 mg/L and of nalidixic acid $90 \mathrm{mg} / \mathrm{L}$. Although the optimum bactericidal concentration of ofloxacin was higher than that of the other two fluoroquinolones it was more bactericidal than either of them when compared at their optimum bactericidal concentrations (fig. 1).

The bactericidal mechanisms of these 4-quinolones against $S$. marcescens were then investigated. Fig. 2 shows that the addition of a bacteriostatic concentration of rifampicin $(300 \mathrm{mg} / \mathrm{L})$, an inhibitor of RNA synthesis, completely abolished the bactericidal activity of nalidixic acid $90 \mathrm{mg} / \mathrm{L}$ or norfloxacin $1.5 \mathrm{mg} / \mathrm{L}$ against $S$. marcescens in nutrient broth. Nalidixic acid $90 \mathrm{mg} / \mathrm{L}$ was also shown

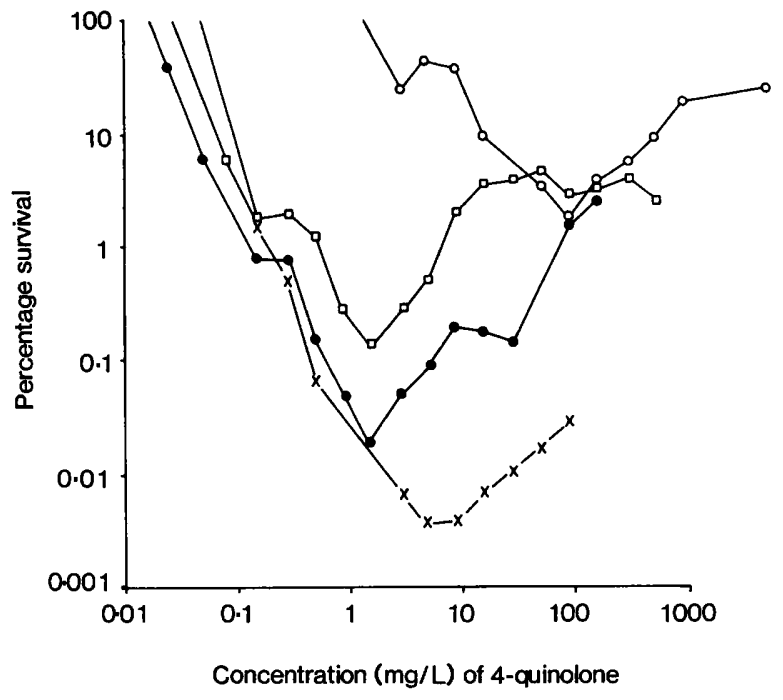

Fig. 1. Survival of $S$. marcescens after exposure for $3 \mathrm{~h}$ to ciprofloxacin $(-0)$, ofloxacin $(x-x)$, nalidixic acid $\left(\mathrm{O}_{-}\right.$ O) or norfloxacin $(\square-\square)$ in nutrient broth at $37^{\circ} \mathrm{C}$.

to be unable to kill non-dividing $S$. marcescens because it was not bactericidal in PBS (fig. 3). Therefore, nalidixic acid possesses only mechanism A against $S$. marcescens. In contrast, norfloxacin was weakly bactericidal against $S$. marcescens in PBS-only $30 \%$ of the bacteria survived after exposure to the drug for $4 \mathrm{~h}$ (compared with $\geqslant 90 \%$ that survived exposure to nalidixic acid for $4 \mathrm{~h}$ ) (fig. 3). Hence, in addition to mechanism A, norfloxacin appears to possess mechanism $\mathrm{C}$, which requires bacterial RNA synthesis for its activity

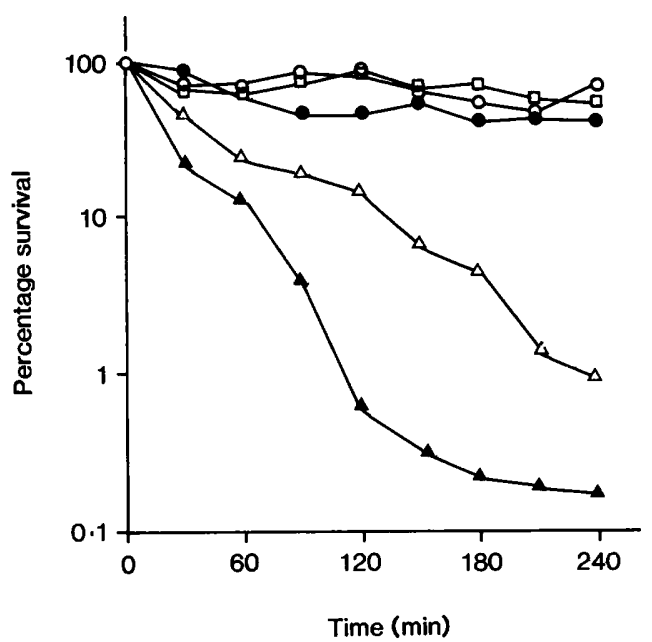

Fig. 2. Survival of $S$. marcescens in nutrient broth at $37^{\circ} \mathrm{C}$ with nalidixic acid $90 \mathrm{mg} / \mathrm{L}(\triangle-\triangle)$, norfloxacin $1.5 \mathrm{mg} / \mathrm{L}(\Delta-\Delta)$, rifampicin $300 \mathrm{mg} / \mathrm{L}(\square-\square)$, nalidixic acid $90 \mathrm{mg} / \mathrm{L}+$ rifampicin $300 \mathrm{mg} / \mathrm{L}(\mathrm{O}-\mathrm{O})$ or norfloxacin $1.5 \mathrm{mg} / \mathrm{L} \mathrm{+} \mathrm{rifampicin}$ $300 \mathrm{mg} / \mathrm{L}(\mathrm{O})$. 




Fig. 3. Survival of $S$. marcescens in $\mathrm{PBS}$ at $37^{\circ} \mathrm{C}$ alone (control, $\mathrm{O}-\mathrm{O}$ ) or with nalidixic acid $90 \mathrm{mg} / \mathrm{L}(-)$ ) or norfloxacin $1.5 \mathrm{mg} / \mathrm{L}(\square-\square)$.

but can kill non-dividing bacteria, against $S$. marcescens.

Fig. 4 shows that the addition of rifampicin $300 \mathrm{mg} / \mathrm{L}$ reduced, but did not completely abolish, the bactericidal activity of ciprofloxacin $1.5 \mathrm{mg} / \mathrm{L}$ or ofloxacin $9 \mathrm{mg} / \mathrm{L}$ against $S$. marcescens in nutrient broth. Hence, ciprofloxacin and ofloxacin exert mechanism $B$ which does not require bacterial

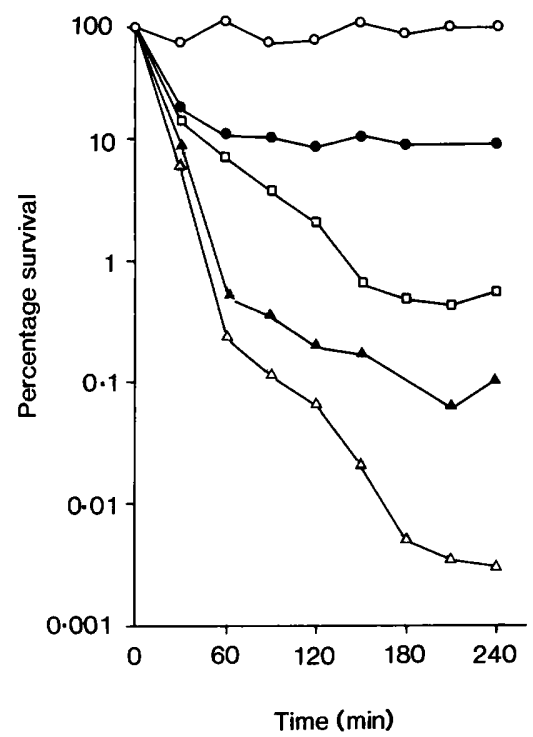

Fig. 4. Survival of $S$. marcescens in nutrient broth at $37^{\circ} \mathrm{C}$ with ciprofloxacin $1.5 \mathrm{mg} / \mathrm{L}(\Delta-\Delta)$, ofloxacin $9 \mathrm{mg} / \mathrm{L}(\triangle-\triangle)$, rifampicin $300 \mathrm{mg} / \mathrm{L}(\mathrm{O}-\mathrm{O})$, ciprofloxacin $1.5 \mathrm{mg} / \mathrm{L}+$ rifampicin $300 \mathrm{mg} / \mathrm{L}(-)$ ) or ofloxacin $9 \mathrm{mg} / \mathrm{L}+$ rifampicin $300 \mathrm{mg} / \mathrm{L}(\square-\square)$.
RNA synthesis for its activity against this species. Furthermore, the reduction in the bactericidal activity of ciprofloxacin and ofloxacin confirms the presence of mechanism A as RNA synthesis is required for its lethal action. When the bactericidal activity of ciprofloxacin $1.5 \mathrm{mg} / \mathrm{L}$ and ofloxacin $9 \mathrm{mg} / \mathrm{L}$ against $S$. marcescens were investigated in PBS, the fluoroquinolones were found to be bactericidal, confirming the presence of mechanism $B$ (fig. 5). The mechanism B possessed by ofloxacin against $S$. marcescens would appear to be more powerful than that of ciprofloxacin, as ofloxacin was significantly more bactericidal than ciprofloxacin in nutrient broth even when rifampicin $300 \mathrm{mg} / \mathrm{L}$ was present or in PBS without rifampicin (figs 4 and 5). This suggests that mechanism $B$ has a more significant role in the bactericidal activity of ofloxacin than in the activity of ciprofloxacin.

\section{Discussion}

All of the 4-quinolones investigated showed a biphasic effect against $S$. marcescens 120 in nutrient broth. The conditions required for the lethal activity of ciprofloxacin, ofloxacin, norfloxacin and nalidixic acid against $S$. marcescens were identical to those required by these drugs against $E$. coli. ${ }^{2,3,8}$ Nalidixic acid exhibited mechanism A only; therefore, RNA synthesis and bacterial cell division are essential for this drug to be bactericidal against $S$. marcescens as well as against $E$. coli. Norfloxacin exerted mechanism $\mathrm{C}$ in addition to mechanism $\mathrm{A}$

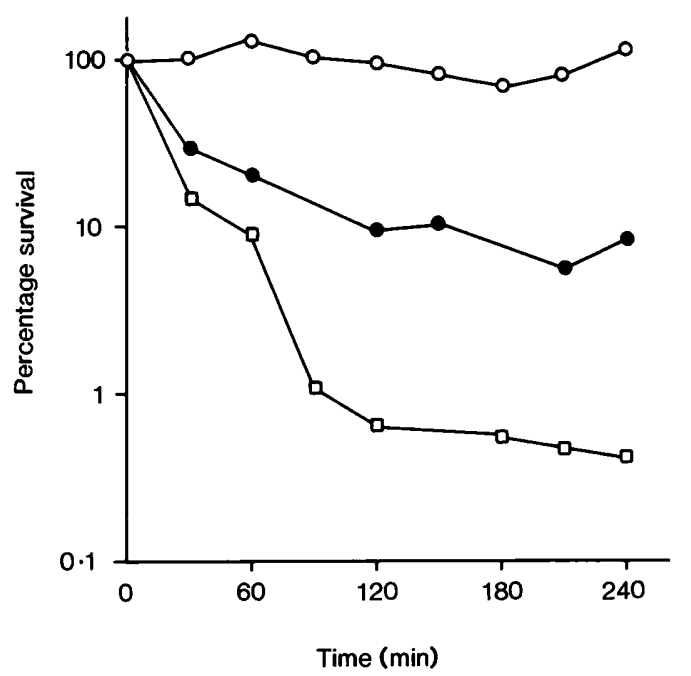

Fig. 5. Survival of $S$. marcescens in $\mathrm{PBS}$ at $37^{\circ} \mathrm{C}$ alone control, $\mathrm{O}-\mathrm{O}$ ) or with ciprofloxacin $1.5 \mathrm{mg} / \mathrm{L}(-)$ ) or ofloxacin $9 \mathrm{mg} / \mathrm{L}(\square-\square)$. 
and was able to kill non-dividing $S$. marcescens although RNA synthesis was a pre-requisite for its lethal activity against this species. However, RNA synthesis was not required for the bactericidal activities of ciprofloxacin and ofloxacin against $S$. marcescens; therefore, these two 4-quinolones possessed mechanism B as well as mechanism A against this species. The mechanism $B$ possessed by ofloxacin against $S$. marcescens was more potent than that of ciprofloxacin. This may explain why, despite the lower optimum bactericidal concentration of ciprofloxacin than of ofloxacin against $S$. marcescens, ofloxacin was more bactericidal at this concentration. In this context, it is interesting to note that ofloxacin displays mechanism $B$ against staphylococci while ciprofloxacin does not. ${ }^{16}$ Hence the mechanism B of ofloxacin may differ from that of ciprofloxacin.

All three fluoroquinolones investigated exerted two bactericidal mechanisms against $S$. marcescens. However, although the mechanisms were the same

\section{REFERENCES}

1. Deitz WH, Cook TM, Goss WA. Mechanism of action of nalidixic acid on Escherichia coli III. Conditions required for lethality. J Bacteriol 1966; 91 : 768-773.

2. Smith JT. Awakening the slumbering potential of the 4quinolone antibiotics. Pharm J 1984; 233 : 299-305.

3. Smith JT, Lewin CS. Chemistry and mechanisms of action of the quinolone antibacterials. In: Andriole V (ed) The quinolones. London, Academic Press. 1988: 2382.

4. Lewin CS, Amyes SGB. The bactericidal activity of DR3355 , an optically active isomer of ofloxacin. $\mathrm{J} \mathrm{Med}$ Microbiol 1989; 30: 227-231.

5. Lewin CS, Amyes SGB, Smith JT. Bactericidal activity of enoxacin and lomefloxacin against Escherichia coli KL16. Eur J Clin Microbiol Infect Dis 1989; 8: 731-733.

6. Lewin, CS, Amyes SGB. Conditions required for the bactericidal activity of pefloxacin and fleroxacin against Escherichia coli KL16. J Med Microbiol 1990; 32: 83-86.

7. Zeiler $\mathbf{H}-J$, Grohe $\mathrm{K}$. The in-vitro and in-vivo activity of ciprofloxacin. Eur J Clin Microbiol 1984; 3: 339-343.

8. Ratcliffe NT, Smith JT. Norfloxacin has a novel bactericidal mechanism unrelated to that of other 4-quinolones. $J$ Pharm Pharmacol 1985; 37: 92.

9. Smith JT. Frequency and expression of mutational resistance to the 4-quinolone antibacterials. Scand $J$ Infect Dis $1986 ; 49$ suppl: 115-123. two as those exhibited against $E$. coli, mutational resistance to the fluoroquinolones at four times their MICs could be detected at significantly higher frequencies in $S$. marcescens. Furthermore, despite both ciprofloxacin and ofloxacin displaying similar bactericidal mechanisms against $S$. marcescens, mutants resistant to ofloxacin but not to ciprofloxacin could be detected at five times their MICs. ${ }^{12}$ Hence the possession of a second bactericidal mechanism by a fluoroquinolone does not necessarily reduce the frequency with which bacteria can mutate to resistance. Thus the suggestion ${ }^{3,9,10}$ that the low frequency of resistance to fluoroquinolones, compared to the non-fluorinated quinolones, in $E$. coli may result from the possession of an additional bactericidal mechanism by the fluoroquinolones may not be correct. However, the possession of an additional bactericidal mechanism would still seem to be beneficial as the fluoroquinolones, unlike the 4-quinolones, are able to kill nondividing bacteria.

10. Lewin CS, Allen RA, Amyes SGB. Potential mechanisms of resistance to the modern fluorinated 4-quinolones. $J$ Med Microbiol 1990; 31: 153-161.

11. Watanabe $\mathbf{M}$, Inoue $\mathbf{M}$, Mitsuhashi $S$. In vitro activity of amifloxacin against outer membrane mutants of the family enterobacteriaceae and frequency of spontaneous resistance. Antimicrob Agents Chemother 1989; 33: $1837-1840$.

12. Smith JT. In-vitro and in-vivo mutation frequencies to resistance. Do they correlate in the long term? In: Crumplin GC (ed) 4-quinolone antibacterial agents in vitro. Heidelberg, Springer Verlag. In press.

13. Schacht $P$, Hullman $R$. Changes of susceptibility of infecting organisms to ciprofloxacin during treatment. Abstracts of the Congress on Bacterial and Parasitic Drug Resistance, Bangkok. 1986: 109.

14. Suzuki K, Nagata Y, Naide Y, Horiba M. Clinical study of strains of Pseudomonas aeruginosa and Serratia marcescens resistant to new quinolones in complicated urinary tract infection. Rev Infect Dis 1989; 11 Suppl 5: S969S970.

15. Lewin CS, Howard BMA, Ratcliffe NT, Smith JT. 4quinolones and the SOS response. $J$ Med Microbiol $1989 ; 29: 139-144$.

16. Lewin CS, Smith JT. Bactericidal mechanisms of ofloxacin. $J$ Antimicrob Chemother 1988; 22 Suppl. C: 1-8. 